\title{
BMJ Open Retrospective analysis of changing characteristics of treatment-seeking smokers: implications for further reducing smoking prevalence
}

\author{
Teresa M Leyro, ${ }^{1}$ Erin E Crew, ${ }^{2}$ Susan W Bryson, ${ }^{3 \dagger}$ Anna Lembke, ${ }^{4}$ \\ Steffani R Bailey, ${ }^{5}$ Judith J Prochaska, ${ }^{2}$ Lisa Henriksen, ${ }^{2}$ Stephen P Fortmann, ${ }^{2,6}$ \\ Joel D Killen, ${ }^{2}$ Diana T Killen, ${ }^{2}$ Sharon M Hall, ${ }^{7}$ Sean P David ${ }^{8}$
}

To cite: Leyro TM, Crew EE, Bryson SW, et al.

Retrospective analysis of changing characteristics of treatment-seeking smokers: implications for further reducing smoking prevalence. BMJ Open 2016;6:e010960. doi:10.1136/bmjopen-2015010960

- Prepublication history and additional material is available. To view please visit the journal (http://dx.doi.org/ 10.1136/bmjopen-2015010960).

†Deceased 7 March 2015

Received 23 December 2015 Revised 4 April 2016 Accepted 29 April 2016

CrossMark

For numbered affiliations see end of article.

Correspondence to Dr Teresa M Leyro; teresa.leyro@rutgers.edu

\section{ABSTRACT}

Objective: The goal of the current study was to empirically compare successive cohorts of treatmentseeking smokers who enrolled in randomised clinical trials in a region of the USA characterised by strong tobacco control policies and low smoking prevalence, over the past three decades.

Design: Retrospective treatment cohort comparison.

Setting: Data were collected from 9 randomised clinical trials conducted at Stanford University and the University of California, San Francisco, between 1990 and 2013.

Participants: Data from a total of 2083 participants were included (Stanford, $n=1356$; University of California San Francisco, $n=727$ ).

Primary and secondary outcomes: One-way analysis of variance and covariance, $\chi^{2}$ and logistic regression analyses were used to examine relations between nicotine dependence, cigarettes per day, depressive symptoms and demographic characteristics among study cohorts.

Results: Similar trends were observed at both settings. When compared to earlier trials, participants in more recent trials smoked fewer cigarettes, were less nicotine-dependent, reported more depressive symptoms, were more likely to be male and more likely to be from a minority ethnic/racial group, than those enrolled in initial trials (all p's $<0.05$ ). Analysis of covariances revealed that cigarettes per day, nicotine dependence and current depressive symptom scores were each significantly related to trial (all p's $<0.001$ ).

Conclusions: Our findings suggest that more recent smoking cessation treatment-seeking cohorts in a low prevalence region were characterised by less smoking severity, more severe symptoms of depression and were more likely to be male and from a minority racial/ ethnic group.

\section{INTRODUCTION}

Cigarette consumption in the USA has declined since $1970,{ }^{1}$ largely the result of a concerted national antismoking public health

\section{Strengths and limitations of this study}

- Data from our randomised controlled trials conducted over several decades allowed us to examine how current treatment-seeking smokers differ from those of the past.

- Data collected from a low smoking prevalence region with effective policy allows us to empirically inform how to further decline smoking prevalence.

- A longitudinal analytic approach was precluded owing to the secondary nature of our analyses and the use of data from unique participants enrolled in different trials that were unequally spaced.

campaign, state-led tobacco control programmes and efficacious smoking cessation interventions. $^{2}{ }^{3}$ Despite this success, the 2000s have been characterised by a less steep decline in prevalence than that observed in earlier decades. ${ }^{4} 5$ The Center for Disease Control has outlined several strategies to reduce smoking in the USA with the goal of decreasing prevalence to $12 \%$ by $2020 ;^{6}$ however, many states have been ineffective in implementing these guidelines, which may partially explain the lack of further decreases in smoking prevalence. Indeed, states with strong tobacco control programmes, such as California, Florida and Massachusetts, have been notably successful in continuing to reduce smoking prevalence into the $2000 \mathrm{~s} ;{ }^{7}$ for example, while the national smoking prevalence is $\sim 18 \%$, the prevalence in California is $12.6 \%{ }^{8}$ However, in states with effective policy and in those without effective policy, tobacco use continues. A crucial first step towards improving cessation outcomes is better characterising individuals whose smoking behaviour persists, despite what is 
presumably effective policy. Although some might argue that samples from states with low current smoking prevalence are atypical, they may be especially useful in predicting future characteristics of smokers to the nation, as smoking rates in other states decline. Together, empirically investigating how current treatment-seeking tobacco users, in the context of effective policy, differ from their counterparts from previous decades may better inform how to further reduce smoking prevalence.

There are two hypotheses that may be used to inform the research on persistent smokers. First, it is possible that they are 'hard core'; that is, characterised by greater cigarette consumption and nicotine dependence. ${ }^{9}$ In support of this hypothesis, it has been posited that current smokers would have stopped, were they able, given major social, health and economic pressure associated with antismoking policies. ${ }^{10}$ However, this hypothesis is challenged by reviews of pharmacological intervention trials, ${ }^{11}$ largely seeking to target physiological nicotine dependence in heavy smokers, which suggest that abstinence rates have not declined over time. $^{2} 312$ The continued success of pharmacological interventions for treatment-seeking smokers challenges the notion that smokers are increasingly untreatable due to greater nicotine dependence and consumption.

Another hypothesis that may explain the less rapid decline in prevalence rates is that current smokers are characterised by a set of demographic and health characteristics that may place them at greater risk for continued cigarette use. In support of this hypothesis, the Center for Disease Control's most recent report indicates that the highest smoking rates are observed among those who are less educated, have lower income, greater specify disability, ${ }^{1}$ and who represent minority racial and ethnic groups. ${ }^{13}$ For example, research indicates that individuals characterised by lower educational attainment ${ }^{14}$ and greater ethnic diversity ${ }^{15-17}$ are less likely to attempt quitting smoking and have worse outcomes. Furthermore, epidemiology studies indicate high smoking prevalence among those with psychiatric illness who are estimated to account for up to $44 \%$ of cigarette consumption. ${ }^{18}$ Although smokers with depression and other mental illnesses, ${ }^{19}{ }^{20}$ when compared to those without psychiatric comorbidities, may equally benefit from treatment, research suggests that these individuals are often excluded from randomised clinical trials and few are designed to directly address their psychiatric symptoms. Together, these factors may contribute to greater smoking prevalence in these groups. Not

\footnotetext{
${ }^{\mathrm{i}}$ According to the CDC functional disability is defined via: (1) self-reported impairments, including vision, hearing, cognition and movement; or (2) limitations in performing activities of daily living (eg, due to physical, mental or emotional problems, the individual needs help performing personal care needs) or instrumental activities of daily living (eg, due to physical, mental or emotional problem, the individual needs help handling routine needs) (http://www.cdc.gov/ mmwr/preview/mmwrhtml/mm6144a2.htm).
}

surprisingly, these groups are broadly characterised by chronic stress and daily stressors, which may in part explain persistent smoking motivated by negative reinforcement. ${ }^{21} 22$

Notably, these two hypotheses are not mutually exclusive; both suggest a smoking population characterised by marked challenges in quitting: one in terms of smoking intake and addiction and the other in terms of smoker characteristics that may potentiate smoking, thereby challenging quitting behaviour. Consideration of these hypotheses may help elucidate difficulty currently observed in driving smoking cessation rates down further. These observations are complicated by the observation that according to the 2014 Surgeon General Report, ${ }^{1}$ the national quit rate has remained stable while the average number of cigarettes smoked per day has been declining. This is considered to in part be due to the overall effectiveness of the tobacco control campaign and economic factors related to changing demographics of smokers. A clearer understanding of characteristics of treatment-seeking smokers in low prevalence regions such as California, and how these characteristics have or have not shifted in the past decade, may help inform approaches towards further decreasing nationwide prevalence in the coming years.

Two notably successful counties in smoking reduction are Santa Clara and San Francisco, which have two of the lowest smoking prevalence rates in the country at $8.3 \%$ and $12.5 \%$, respectively. ${ }^{23}$ In the near future, as other regions implement effective policies, and smoking rates decline, the smokers remaining in Santa Clara and San Francisco counties may be increasingly characteristic of smokers nationwide. Thus, the purpose of this study was to examine differences in treatment-seeking smokers smoking behaviour, as well as demographic, and psychosocial characteristics, via comparing these characteristics across several cohorts who enrolled in randomised controlled cessation trials in a low prevalence region (ie, Santa Clara and San Francisco counties, California).

\section{METHODS}

\section{Procedure}

We analysed baseline data from treatment-seeking smokers who enrolled in nine studies. Five studies were conducted over a 20-year period (1994-2013) at Stanford University ${ }^{24-27}$ and four studies were conducted over a 10-year period (1990-2000) at the University of California San Francisco (UCSF).$^{28-31}$ All trials received Institutional Review Board approval.

For all trials, participants were recruited via local advertising, public service announcements and flyers. Descriptions of the clinical trials are below (see online supplementary appendix for additional information). Participants were adults who smoked at least 10 cigarettes per day. Exclusion criteria were similar for all trials and included current major depression, substance abuse or medical contraindications. Comparisons were made 
within each treatment site given similar inclusion/exclusion criteria and intervention approaches. In addition, this allowed for later comparison of findings between the two research sites.

\section{Studies}

All study designs were randomised controlled trials: five at Stanford and four at UCSF. Stanford Trial 1 evaluated paroxetine for smoking cessation $(\mathrm{N}=224){ }^{27}$ Participants also received the nicotine patch and behavioural counselling. Trial 2 evaluated extended treatment with bupropion sustained release (SR) $(\mathrm{N}=362){ }^{24}$ Participants received open label treatment with nicotine patch, bupropion SR and relapse prevention training, followed by extended bupropion SR or matching placebo. Trial 3 tested extended cognitive behavioural therapy (CBT) for smoking cessation $(\mathrm{N}=304){ }^{26}$ Participants received open label treatment with nicotine patch, bupropion SR and CBT, followed by either extended CBT or brief, general support. Trial 4 tested transdermal selegiline $(\mathrm{N}=243) .{ }^{25}$ All participants received CBT. Trial 5 evaluated extended CBT for smoking cessation $(\mathrm{N}=223)$. Participants received open label treatment with cessation medications (ie, bupropion SR, nicotine patch and varenicline) and CBT followed by extended CBT or brief follow-up calls. This trial was recently completed.

UCSF Trial 1 tested CBT with nicotine gum for smoking cessation $(\mathrm{N}=149) .{ }^{30}$ Trial 2 tested nortriptyline and CBT for smoking cessation $(\mathrm{N}=199) .{ }^{31}$ Trial 3 tested a psychological intervention and antidepressant treatment (bupropion, nortriptyline or placebo) for smoking cessation ( $\mathrm{N}=219) .{ }^{29}$ Participants received psychological intervention or medication management. Trial 4 tested nortriptyline for smoking cessation $(\mathrm{N}=160) .^{28}$ All participants received the nicotine patch. Participants were also randomised to receive brief or extended treatment.

\section{Measures}

Baseline variables included demographic characteristics (age, sex, marital status, race/ethnicity and education), and information on perceived health, and smoking behaviour. Baseline height and weight were obtained to calculate body mass index. All variables were identical across trials within a given site. While in some cases Stanford and UCSF used different measures for the same variable, most variables were identical between academic sites, allowing for discussion of similarities and differences in outcomes.

Smoking: Participants reported their usual number of cigarettes smoked per day upon study entry.

Nicotine dependence: Stanford used the 5-item Modified Fagerström Tolerance Questionnaire to assess the level of tobacco dependence, ${ }^{32}$ whereas UCSF used the Fagerström Test for Cigarette Dependence (FTCD). ${ }^{33}$ Each measure includes several items used to determine self-reported level of dependence on cigarettes (eg, Which cigarette would you hate most to give up? Do you smoke more frequently during the first hours of waking than during the rest of the day?). ${ }^{32} 33$

Current depressive symptoms: To assess past week depressive symptomatology, Stanford used the Center for Epidemiological Studies Depression instrument (CES-D) ${ }^{34}$ and UCSF used the 21-item Beck Depression Inventory (BDI) ${ }^{35}$ Both are widely used measures of depression with good sensitivity and specificity, high internal consistency, high content validity and high construct validity. Higher scores suggest worse depressive symptoms with scores $>16$ and 10, suggestive of a major depressive episode according to the CES-D ${ }^{34}$ and BDI, ${ }^{35}$ respectively.

\section{Analytical approach}

Analyses were conducted using IBM SPSS V.22.0. The two trial sites (Stanford and UCSF) were analysed separately. Separate analysis of data from two independent sites, within the same geographic region, allows us to identify whether similar patterns emerge. One-way analysis of variance (ANOVA: continuous) and $\chi^{2}$ (categorical) tests were used to compare baseline variables across the studies. Post hoc comparisons with Bonferroni corrections were used to identify which trials significantly differed on characteristics examined. Effect sizes were calculated using $\eta^{2}$ for continuous measures and Cramer's V for categorical variables. These initial analyses informed subsequent one-way analysis of covariance (ANCOVA) analyses concurrently examining cigarette consumption, dependence and depression symptoms, after adjusting for other characteristics that would serve as unlikely treatment targets, in relation to the site trial sample. Specifically, for the Stanford and UCSF analyses, we included age, minority status, marital or partner status and sex as covariates.

\section{RESULTS}

\section{Stanford trials}

ANOVA revealed significant differences across the five Stanford trials $(\mathrm{N}=1356)$ in mean cigarettes consumed per day $\left(\mathrm{F}_{4,1348}=30.3, \mathrm{p}<0.001\right)$, with the average reported cigarettes per day lower in each successive trial. A statistically significant difference in nicotine dependence scores was also observed $\left(\mathrm{F}_{4,1344}=21.2, \mathrm{p}<0.001\right)$; here, post hoc analyses indicated that baseline nicotine dependence scores in the first trial were significantly lower than the subsequent three trials, and were similar to the most recent trial. There was a significant difference in depressive symptom scores reported among trials $\left(\mathrm{F}_{4,1345}=7.2\right.$, $\mathrm{p}<0.001$ ), with post hoc analyses indicating that participants in the most recent trial reported significantly greater depressive than those enrolled in the initial four trials. In addition, a significant difference in age was observed among trials; post hoc analyses indicated that participants enrolled in the first and third trials were significantly older upon study entry than those enrolled in the most recent trial $\left(\mathrm{F}_{4,1348}=3.4, \mathrm{p}=0.01\right)$. Trials also differed significantly in terms of sex, marital status and 
race/ethnicity, such that those in more recent trials were more likely to be male $\left(\chi^{2}(4)=17.6 \mathrm{p}=0.001\right)$, unmarried $\left(\chi^{2}(4)=18.5, p=0.001\right)$ and from a minority ethnic/racial group $\left(\chi^{2}(4)=19.4, p<0.001\right)$ than those in earlier trials.

Separate one-way ANCOVAs were conducted to determine whether there was a statistically significant difference among study cohorts for a given site on baseline values of cigarettes smoked daily, nicotine dependence and depression, controlling for age, minority status, marital status and sex. A significant effect for study group in terms of cigarettes smoked daily at study entry was observed $\left(\mathrm{F}_{4,1342}=27.89, \mathrm{p}<0.001\right)$. Post hoc comparisons revealed that participants in the first trial reported smoking significantly more cigarettes per day than those enrolled in the next four trials (all p's $<0.001$ ), whereas those enrolled in the middle three trials did not significantly differ from each other in terms of cigarettes smoked daily. However, those enrolled in the most recent trial reported smoking significantly fewer cigarettes daily than those enrolled in the first three trials (all p's $<0.05$ ), with a non-statistically significant difference when compared with those enrolled in the fourth trial $(\mathrm{p}=0.08)$.

Also, a significant effect for study group in terms of baseline nicotine dependence was observed $\left(\mathrm{F}_{4,1338}=21.04\right.$, $\mathrm{p}<0.001)$. Post hoc comparisons revealed that participants enrolled in the first trial were significantly less nicotinedependent than those enrolled in the next two trials ( p's $<0.01$ ), and participants enrolled in the second and third trials were significantly more nicotine-dependent than those enrolled in the first, fourth, and fifth trials ( p's $<0.01)$. Interestingly, participants enrolled in the most recent trial were less nicotine-dependent than those enrolled in the second and third trials ( $p$ 's $<0.001)$, but dependence levels were not significantly different than that of participants enrolled in the fourth trial $(p=0.08$; see table 2).

Finally, a significant effect for study group in terms of baseline depression was observed $\left(\mathrm{F}_{4,1339}=5.64, \mathrm{p}<0.001\right)$. Post hoc comparisons revealed that after controlling for the aforementioned demographic variables, participants in the fifth trial reported significantly greater depression scores at baseline compared to those enrolled in trials $1-4$ (all p's $<0.05$ ), whose scores were not significantly different from each other (table 1 ).

\section{UCSF trials}

ANOVA revealed a significant difference in mean cigarettes smoked per day $\left(\mathrm{F}_{3,723}=10.4, \mathrm{p}<0.001\right)$ among trials, with post hoc analyses indicating that participants enrolled in the first two trials smoked significantly more cigarettes per day when compared to those enrolled in trials 3 and 4, with no significant difference between trials 1 and 2 and between trials 3 and 4 . There was a significant difference in the level of nicotine dependence among trials $\left(\mathrm{F}_{3,709}=24.0, \mathrm{p}<0.001\right)$, with post hoc comparisons indicating that nicotine dependence scores were significantly lower in the subsequent trials when compared to the first trial. In addition, there was a significant difference in current depressive symptom scores across the four trials $\left(\mathrm{F}_{3,716}=9.7, \mathrm{p}<0.001\right)$, with post hoc analyses suggesting that current depressive symptom scores were significantly greater in the past three trials when compared to the first. Participants in recent trials were more likely to be male $\left(\chi^{2}(3)=9.5, p=0.02\right)$ and from a minority ethnic/racial group $\left(\chi^{2}(3)=9.3, p=0.03\right)$ than those enrolled in the initial trials. Unlike the Stanford trials, age upon study entry $\left(\mathrm{F}_{3,219}=1.8, \mathrm{p}=0.15\right)$ and partner status $\left(\chi^{2}(3)=6.7, p=0.08\right)$ did not significantly differ among trials.

Separate one-way ANCOVAs were conducted to determine whether there was a statistically significant difference among study cohorts and baseline values of cigarettes smoked daily, nicotine dependence and depression, controlling for age, minority status, partner and sex. A significant effect for study group in terms of cigarettes smoked daily at baseline was observed $\left(\mathrm{F}_{3,712}=9.63, \mathrm{p}<0.001\right)$. Post hoc comparisons revealed that participants in the most recent trial reported smoking significantly fewer cigarettes than those enrolled in the first $(\mathrm{p}<0.001)$ and second trials $(p=0.003)$. Differences in cigarettes smoked daily between the most recent and third trial failed to reach our selected alpha level of $\mathrm{p}<0.05 \quad(\mathrm{p}=0.06)$.

Also, a significant effect for study group in terms of baseline nicotine dependence was observed $\left(\mathrm{F}_{3,699}=22.67\right.$, $\mathrm{p}<0.001)$. Post hoc comparisons revealed that participants enrolled in the first trial were significantly more nicotinedependent than those enrolled in the latter three trials, and participants enrolled in the second were significantly more nicotine-dependent than those enrolled in the most recent two trials (all p's $<0.003$ ).

Finally, a significant effect for study group in terms of baseline depression was observed $\left(\mathrm{F}_{3,706}=9.65, \mathrm{p}<0.001\right)$. Post hoc comparisons revealed that after adjusting for the aforementioned demographic variables, participants in the first trial reported significantly lower depression scores at baseline compared to those enrolled in later trials (table 2).

\section{DISCUSSION}

Despite increased implementation of tobacco control policies, many continue to smoke and the past decade has been characterised by a less steep decline in smoking prevalence than that observed in previous decades, suggesting the need for additional and more concerted efforts. Among successive treatment-seeking cohorts enrolled in nine clinical trials over the course of two decades in Northern California, we found similar changes in cohort demographics over time between two academic sites. Both sites consistently found that more recent trial samples smoked fewer cigarettes and were less nicotine-dependent, and reported more depressive symptoms In addition, there was some evidence that 
Table 1 Stanford trials: comparisons of baseline characteristics

\begin{tabular}{|c|c|c|c|c|c|c|c|c|c|}
\hline Variable & $\begin{array}{l}\text { Trial } 1 \\
\mathrm{~N}=224 \\
\mathrm{M} \text { (SD) }\end{array}$ & $\begin{array}{l}\text { Trial } 2 \\
\mathrm{~N}=362 \\
\mathrm{M}(\mathrm{SD})\end{array}$ & $\begin{array}{l}\text { Trial } 3 \\
\mathrm{~N}=304 \\
\mathrm{M}(\mathrm{SD})\end{array}$ & $\begin{array}{l}\text { Trial } 4 \\
\mathrm{~N}=243 \\
\mathrm{M} \text { (SD) }\end{array}$ & $\begin{array}{l}\text { Trial } 5 \\
\mathrm{~N}=223 \\
\mathrm{M} \text { (SD) }\end{array}$ & Significance* $^{*}$ & Effect size* & Significance & Effect size $^{\star}$ \\
\hline Cigarettes per day & $25.6(11.5)$ & $20.2(8.2)$ & $20.1(7.4)$ & $19.8(7.1)$ & $17.4(6.6)$ & $\begin{array}{l}F(4,1348)=30.3 \\
p<0.001\end{array}$ & $0.08^{\mathrm{es}}$ & $\begin{array}{l}F(4,1342)=27.9 \\
p<0.001\end{array}$ & $0.08^{\mathrm{es}}$ \\
\hline Nicotine dependence $\ddagger$ & $14.8(2.5)$ & $16.6(3.5)$ & $16.5(3.7)$ & $15.4(2.9)$ & $14.7(3.0)$ & $\begin{array}{l}\mathrm{F}(4,1344)=21.2 \\
\mathrm{p}<0.001\end{array}$ & $0.06^{\mathrm{es}}$ & $\begin{array}{l}F(4,1338)=21.0 \\
p<0.001\end{array}$ & $0.06^{\mathrm{es}}$ \\
\hline Current depressive symptoms§ & $7.6(7.6)$ & $7.8(6.6)$ & $6.7(6.8)$ & $7.7(7.8)$ & $10.0(7.7)$ & $\begin{array}{l}F(4,1345)=7.2 \\
p<0.001\end{array}$ & $0.02^{\mathrm{es}}$ & $\begin{array}{l}F(4,1339)=5.6 \\
p<0.001\end{array}$ & $0.01^{\mathrm{es}}$ \\
\hline Age & $46.1(11.5)$ & $45.6(10.9)$ & $45.9(10.9)$ & $44.1(10.7)$ & $43.1(11.9)$ & $\begin{array}{l}F(4,1348)=3.4 \\
p=0.01\end{array}$ & $0.01^{\mathrm{es}}$ & & \\
\hline Body mass index & $27.5(5.0)$ & $28.0(5.3)$ & $28.0(5.7)$ & $28.4(5.5)$ & $27.7(6.0)$ & $\begin{array}{l}F(4,1344)=0.85 \\
p=0.49\end{array}$ & $0.003^{\mathrm{es}}$ & & \\
\hline$\%$ Female & 46.0 & 46.1 & 40.2 & 30.5 & 39.9 & $\begin{array}{l}\chi^{2}(4)=17.6 \\
p=0.001\end{array}$ & $0.11^{v}$ & & \\
\hline$\%$ Married & 46.0 & 47.2 & 49.5 & 39.1 & 33.2 & $\begin{array}{l}\chi^{2}(4)=18.5 \\
p=0.001\end{array}$ & $0.12^{v}$ & & \\
\hline$\%$ Minority & 12.5 & 22.2 & 24.3 & 26.3 & 28.3 & $\begin{array}{l}\chi^{2}(4)=19.4 \\
p<0.001\end{array}$ & $0.12^{v}$ & & \\
\hline$\%$ College degree & 33.0 & 27.7 & 33.6 & 30.5 & 33.6 & $\begin{array}{l}\chi^{2}(4)=3.8 \\
p=0.43\end{array}$ & $0.05^{\mathrm{v}}$ & & \\
\hline
\end{tabular}




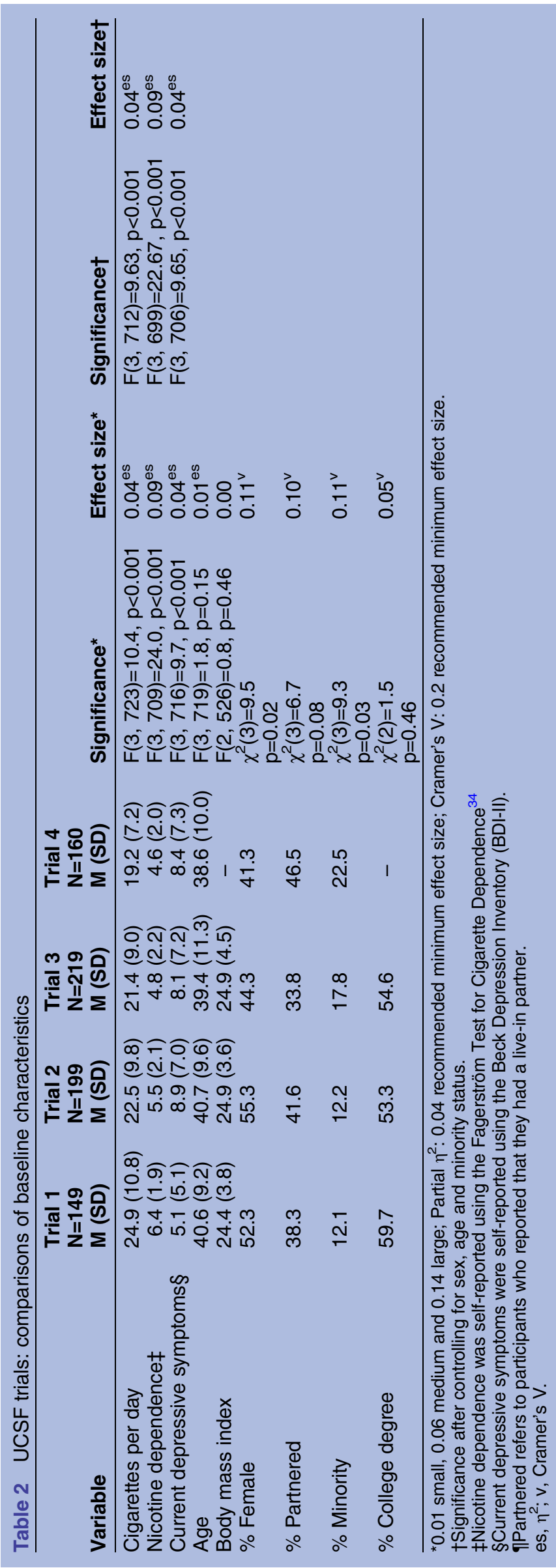

more recent trial samples were more likely to be men, from a minority/ethnic group and younger.

Our findings suggest that greater consumption and dependence are not characteristics of persistent, treatment-seeking, smokers. However, this finding should be considered in the context of recent epidemiologic research, indicating that less cigarette consumption among smokers in the past 25 years is not paralleled by a decrease in cotinine levels. ${ }^{36}$ This may also explain why the Stanford findings reported greater consumption in the first cohort, which was counter-intuitively characterised by less dependence than the middle cohorts. Consistent with this observation, recent research, although controversial, has suggested that nicotine content in cigarettes has increased. ${ }^{36}$ With greater public restrictions on combustible cigarettes and greater dual use of tobacco and electronic nicotine delivery systems (eg, e-cigarettes), a narrow assessment of only consumption of cigarettes, as captured by the FTCD, ${ }^{32} 33$ may underestimate severity of dependence. ${ }^{37} 38$ Therefore, differences in dependence in the current investigation, which are greatly influenced by consumption, should be interpreted with caution.

Also, there is a possibility that despite reduced consumption, current treatment-seeking smokers may not be at reduced risk for negative physiological outcomes associated with smoking; future work must continue to examine whether observed changes in nicotine dependence and cigarette consumption are paralleled by decreases in cotinine and plasma nicotine levels. Finally, individuals who reported smoking fewer than 10 cigarettes per day were excluded from these trials. Longitudinal data on smoking trends from 1965 to 2007 in California suggest a significant decline in heavy $(\geq 20$ cigarette/day) smoking with a smaller but steady decline in moderate (10-19 cigarettes/day) smoking, during this time. ${ }^{39}$ This is matched by decreases in per capita consumption during the same time period. ${ }^{40}$ Notably, these data are not accompanied by an increase in light smoking (0-9 cigarettes/day), and instead suggest a decline in heavy and moderate smoking initiation driven by younger cohorts. ${ }^{39}$ Given our studies enrolled only smokers who reported smoking at least 10 cigarettes/ daily, our findings may be a rather conservative snapshot of the observed cohort differences in cigarette consumption.

The study provides some support for the notion that more recent treatment-seeking smokers are characterised by significantly greater self-reported depressive symptoms, when compared to prior trials. Given study sites excluded smokers with a current DSM-IV diagnosis of major depression or bipolar disorder, this finding may be an underestimation of the increase in depressive symptoms among current treatment-seeking smoke. Research has indeed suggested that negative reinforcement plays a pivotal role in smoking maintenance in that stress and sensitivity to nicotine withdrawal may potentiate smoking behaviour. ${ }^{21}$ Thus, smokers who are 
vulnerable to greater depressive symptoms may experience greater difficulty abstaining from smoking and may be more apt to reflexively rely upon smoking to manage negative affect than those without such symptoms. ${ }^{22} 41$ Therefore, it is possible that current treatment-seeking smokers will be increasingly characterised by high depressive symptoms, and the field should continue to investigate interventions for these individuals. It is also notable that a recent meta-analysis by Taylor et $a l^{41}$ found evidence that cessation resulted in improved ratings of depression, anxiety and stress, among smokers with and without a baseline psychiatric illness. This highlights the likely bidirectional role of smoking and negative affect, and the potential to improve multiple areas of functioning via cessation.

We found that more recent trial samples were younger (Stanford only) and more likely to be unmarried, of minority status (ie, Caucasian) and male. Although our data precluded clarification of a shift towards a particular ethnic group, it is important to note that California has the highest number of immigrants of any state. Thus, this finding may not generalise to other regions. It will be important to examine whether the observed relations of cohort with tobacco use and dependence indicators as well as depressive symptoms are mediated by age, education or immigrant status, given these characteristics may be associated.

The finding that current treatment-seeking smokers are more likely to be unmarried may indicate that those with partners have experienced more quit success, consistent with a large body of evidence suggesting having a partner is associated with less lapse, ${ }^{42}$ greater quit resumption $^{43}$ and cessation success. ${ }^{44}$ In addition, marital status is associated with a decreased risk of depression; ${ }^{45}$ therefore, future research in this area should consider the relation between partner status, negative affect and smoking. Finally, recent research has indicated a surge in cigarette smoking in young adults ${ }^{46}$ and that these smokers have a unique set of characteristics when compared to older smokers, including lower daily consumption and a higher probability of being unmarried or without a partner.

While clinically meaningful, the current results are limited. First, our participants are likely not representative of treatment-seeking smokers in regions outside of the Bay Area, which is an ethnically diverse area with strong tobacco control policies. Although our results suggested less consumption and lower dependence in more recent cohorts, future research ought to consider this finding in light of new research suggesting no difference in cotinine levels between smokers in 1988-1994 vs 1999-2012. ${ }^{36}$ Furthermore, study exclusionary criteria likely resulted in less variability in smoking intensity and comorbid psychiatric illnesses. Research in other low prevalence regions and/or in treatment-seeking smokers enrolled in less intensive interventions is necessary. In addition to addressing these limitations, it is important to re-emphasise that many of the observed characteristics are associated. For example, younger smokers smoke fewer cigarettes and marital status is associated with depressive symptoms. Despite these limitations, the current study provided a novel opportunity to examine group differences in treatment-seeking smokers in a low prevalence region over multiple decades. Researchers and treatment providers may benefit from considering these shifting characteristics when developing and applying smoking intervention programmes.

\section{Author affiliations}

${ }^{1}$ Department of Psychology, Rutgers, The State University of New Jersey, New Brunswick, New Jersey, USA

${ }^{2}$ Department of Medicine, Stanford Prevention Research Center, Stanford University School of Medicine, Stanford University, Stanford, California, USA

${ }^{3}$ Stanford Prevention Research Center, Stanford University, Palo Alto, California, USA

${ }^{4}$ Department of Psychiatry, Stanford University School of Medicine, Stanford, California, USA

${ }^{5}$ Department of Family Medicine, Oregon Health \& Sciences University, Portland, Oregon, USA

${ }^{6}$ Kaiser Permanente Center for Health Research, Northwest, Portland, Oregon, USA

${ }^{7}$ Department of Psychiatry, San Francisco Treatment Research Center, University of California, San Francisco, California, USA

${ }^{8}$ Department of Medicine, Division of General Medical Disciplines, Stanford University School of Medicine, Stanford, California, USA

Contributors TML, EEC and SPD designed the current study. TML and EEC conducted literature search. TML, SWB and SPD conducted the analyses. TML and EEC drafted the manuscript. SMH, SPD, JDK and SPF designed the original investigations and served as the principle investigator(s) for each trial whose data were used in the current investigation. JDK, SPD, AL, SRB, LH and JJP contributed substantially to the original trial designs and data collection. SMH, SPD and JJP contributed substantially to the current study rationale, approach and discussion. Together, all authors contributed to and have approved the final manuscript.

Funding This work was supported by the University of California Tobacco-Related Disease Research Program, grant numbers RT 0041 and 21BT-0018, the National Cancer Institute, grant number CA 090300 and the National Institute on Drug Abuse, grant numbers ROI DA 017441, R0I DA 017457, P50 DA009253, K05DA016752, R01 DA02538 and T32DA007250.

Competing interests JJP has served as a paid expert witness for the plaintiff counsel in cases against tobacco companies and has provided consultation to Pfizer, which makes medications for quitting smoking.

Ethics approval Institutional Review Board.

Provenance and peer review Not commissioned; externally peer reviewed.

Data sharing statement Statistical code and data set available for UCSF are available from the corresponding author at teresa.leyro@rutgers.edu and for Stanford at spdavid@stanford.edu.

Open Access This is an Open Access article distributed in accordance with the Creative Commons Attribution Non Commercial (CC BY-NC 4.0) license, which permits others to distribute, remix, adapt, build upon this work noncommercially, and license their derivative works on different terms, provided the original work is properly cited and the use is non-commercial. See: http:// creativecommons.org/licenses/by-nc/4.0/

\section{REFERENCES}

1. US Department of Health and Human Services. The health consequences of smoking-50 years of progress: a report of the Surgeon General. Atlanta, GA: US Department of Health and 
Human Services, Centers for Disease Control and Prevention, National Center for Chronic Disease Prevention and Health Promotion, Office on Smoking and Health. 2014;17.

2. Hughes JR, Stead LF, Hartmann-Boyce J, et al. Antidepressants for smoking cessation. Cochrane Database Syst Rev 2014:CD000031.

3. Stead LF, Perera R, Bullen C, et al. Nicotine replacement therapy for smoking cessation. Cochrane Database Syst Rev 2012;11: CD000146.

4. Irvin JE, Brandon TH. The increasing recalcitrance of smokers in clinical trials. Nicotine Tob Res 2000;2:79-84.

5. Irvin JE, Hendricks PS, Brandon TH. The increasing recalcitrance of smokers in clinical trials II: pharmacotherapy trials. Nicotine Tob Res 2003;5:27-35.

6. USDHHS UDoHHS. The changing landscape of tobacco control In: Promotion OoDPaH, ed. Atlanta, GA, 2011.

7. Miller LS, Max W, Sung HY, et al. Evaluation of the economic impact of California's Tobacco Control Program: a dynamic model approach. Tob Control 2010;19(Suppl 1):i68-76.

8. CDC CfDCaP. Current cigarette smoking among adults - United States, 2005-2013. MMWR Morb Mortal Wkly Rep 2014;63:1108-12.

9. Hughes JR. The hardening hypothesis: is the ability to quit decreasing due to increasing nicotine dependence? A review and commentary. Drug Alcohol Depend 2011;117:111-17.

10. Warner KE, Burns DM. Hardening and the hard-core smoker: concepts, evidence, and implications. Nicotine Tob Res 2003;5:37-48

11. Cohen JE, McDonald PW, Selby P. Softening up on the hardening hypothesis. Tob Control 2012;21:265-6.

12. Cahill K, Stead LF, Lancaster T. Nicotine receptor partial agonists for smoking cessation. Cochrane Database Syst Rev 2012:CD006103.

13. Agaku IT, King BA, Dube SR. Current cigarette smoking among adults_United States 2005-2012. MMWR Morb Mortal Wkly Rep 2014:63:29-34.

14. Wetter DW, Cofta-Gunn L, Irvin JE, et al. What accounts for the association of education and smoking cessation? Prev Med 2005;40:452-60.

15. Cokkinides VE, Halpern MT, Barbeau EM, et al. Racial and ethnic disparities in smoking-cessation interventions: analysis of the 2005 National Health Interview Survey. Am J Prev Med 2008;34:404-12.

16. Lawrence D, Graber JE, Mills SL, et al Smoking cessation interventions in U.S. racial/ethnic minority populations: an assessment of the literature. Prev Med 2003;36:204-16.

17. Trinidad DR, Pérez-Stable EJ, White MM, et al. A nationwide analysis of US racial/ethnic disparities in smoking behaviors, smoking cessation, and cessation-related factors. Am J Public Health 2011;101:699-706.

18. Lasser K, Boyd JW, Woolhandler S, et al. Smoking and mental illness: a population-based prevalence study. JAMA 2000;284:2606-10.

19. Gierisch JM, Bastian LA, Calhoun PS, et al. Smoking cessation interventions for patients with depression: a systematic review and meta-analysis. J Gen Intern Med 2012;27:351-60.

20. Hitsman B, Borrelli B, McChargue DE, et al. History of depression and smoking cessation outcome: a meta-analysis. J Consult Clin Psych 2003;71:657-63.

21. Baker TB, Piper ME, McCarthy DE, et al. Addiction motivation reformulated: an affective processing model of negative reinforcement. Psychol Rev 2004;111:33-51.

22. Kassel JD, Stroud LR and Paronis CA. Smoking, stress, and negative affect: correlation, causation, and context across stages of smoking. Psych Bull 2003;129:270-304.

23. California Department of Public Health, California Tobacco Contro Program. Adult smoking prevalence-Santa Clara, CA. County and Statewide Archive of Tobacco Studies (C-STATS). 2008.
24. Killen JD, Fortmann SP, Murphy GM Jr, et al. Extended treatment with bupropion SR for cigarette smoking cessation. J Consult Clin Psychol 2006;74:286-94.

25. Killen JD, Fortmann SP, Murphy GM Jr, et al. Failure to improve cigarette smoking abstinence with transdermal selegiline+cognitive behavior therapy. Addiction 2010;105:1660-8.

26. Killen JD, Fortmann SP, Schatzberg AF, et al. Extended cognitive behavior therapy for cigarette smoking cessation. Addiction 2008;103:1381-90.

27. Killen JD, Fortmann SP, Schatzberg AF, et al. Nicotine patch and paroxetine for smoking cessation. J Consult Clin Psychol 2000;68:883-9.

28. Hall SM, Humfleet GL, Reus VI, et al. Extended nortriptyline and psychological treatment for cigarette smoking. Am J Psychiatry 2004;161:2100-7.

29. Hall SM, Humfleet GL, Reus VI, et al. Psychological intervention and antidepressant treatment in smoking cessation. Arch Gen Psychiatry 2002;59:930-6.

30. Hall SM, Munoz RF, Reus VI. Cognitive-behavioral intervention increases abstinence rates for depressive-history smokers. J Consult Clin Psychol 1994:62:141-6.

31. Hall SM, Reus VI, Munoz RF, et al. Nortriptyline and cognitive-behavioral therapy in the treatment of cigarette smoking. Arch Gen Psychiatry 1998;55:683-90.

32. Fagerström K. Measuring degree of physical dependence to tobacco smoking with reference to individualization of treatment. Addict Behav 1978;3:235-41.

33. Fagerström K. Determinants of tobacco use and renaming the FTND to the Fagerström Test for Cigarette Dependence. Nicotine Tob Res 2012;14:75-8

34. Radloff LS. The CES-D scale: a self-report depression scale for research in the general population. Appl Psych Meas 1977;1:385-401.

35. Beck AT, Ward $\mathrm{CH}$, Mendelson $\mathrm{M}$, et al. An inventory for measuring depression. Arch Gen Psychiatry 1961;4:561-71.

36. Jarvis MJ, Giovino GA, O'Connor RJ, et al. Variation in nicotine intake among U.S. cigarette smokers during the past 25 years: evidence from NHANES surveys. Nicotine Tob Res 2014;16:1620-8.

37. Issa JS. A new nicotine dependence score and a new scale assessing patient comfort during smoking cessation treatment. J Bras Pneumol 2012;38:761-5.

38. Frost-Pineda K, Appleton S, Fisher M, et al. Does dual use jeopardize the potential role of smokeless tobacco in harm reduction? Nicotine Tob Res 2010;12:1055-67.

39. Pierce JP, Messer K, White MM, et al. Prevalence of heavy smoking in California and the United States, 1965-2007. JAMA 2011;305:1106-12.

40. Orzechowski W, Walker R. The tax burden on tobacco. Historical compilation 2008;39.

41. Taylor G, McNeill A, Girling A, et al. Change in mental health after smoking cessation: systematic review and meta-analysis. BMJ 2014;348:g1151.

42. Japuntich SJ, Leventhal AM, Piper ME, et al. Smoker characteristics and smoking-cessation milestones. Am J Prev Med 2011;40:286-94.

43. Leyro TM, Hendricks PS, Hall SM. If at first you don't succeed: characterization of smokers with late smoking abstinence onset. Addict Behav 2015;45:34-8.

44. Lee CW, Kahende J. Factors associated with successful smoking cessation in the United States, 2000. Am J Public Health 2007:97:1503-9.

45. Yan XY, Huang SM, Huang CQ, et al. Marital status and risk for late life depression: a meta-analysis of the published literature. $J$ Int Med Res 2011;39:1142-54.

46. Hammond D. Smoking behaviour among young adults: beyond youth prevention. Tob Control 2005;14:181-5. 